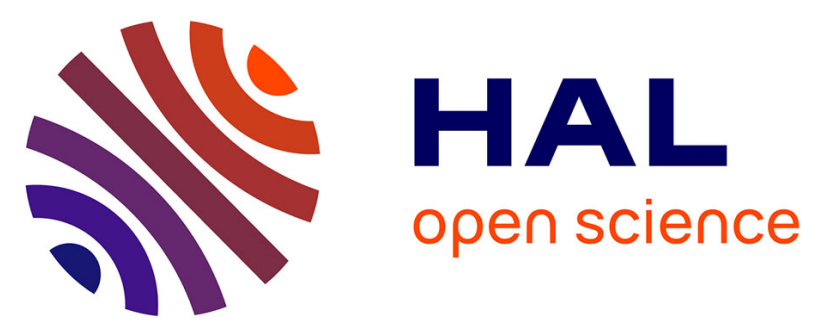

\title{
LDO-assisted Voltage Selector over 0.5-to-1V VDD range for fine Grained DVS in FDSOI 28nm with 200ns/V Controlled Transition
}

Anthony Quelen, Guilherme Migliato Marega, Sylvain Bouquet, Ivan

Miro-Panades, Gaël Pillonnet

\section{To cite this version:}

Anthony Quelen, Guilherme Migliato Marega, Sylvain Bouquet, Ivan Miro-Panades, Gaël Pillonnet. LDO-assisted Voltage Selector over 0.5-to-1V VDD range for fine Grained DVS in FDSOI 28nm with 200ns/V Controlled Transition. 44th European Solid-State Circuits Conference ESSCIRC, 2018, Dresde, Germany. hal-01887166

\section{HAL Id: hal-01887166 https://hal.science/hal-01887166}

Submitted on 3 Oct 2018

HAL is a multi-disciplinary open access archive for the deposit and dissemination of scientific research documents, whether they are published or not. The documents may come from teaching and research institutions in France or abroad, or from public or private research centers.
L'archive ouverte pluridisciplinaire HAL, est destinée au dépôt et à la diffusion de documents scientifiques de niveau recherche, publiés ou non, émanant des établissements d'enseignement et de recherche français ou étrangers, des laboratoires publics ou privés. 


\title{
LDO-assisted Voltage Selector over 0.5-to-1V VDD range for fine Grained DVS in FDSOI 28nm with 200ns/V Controlled Transition
}

\author{
Anthony Quelen, Guilherme Migliato Marega, Sylvain Bouquet, Ivan Miro-Panades, Gaël Pillonnet \\ Univ. Grenoble Alpes, F-38000 Grenoble, France \\ CEA, LETI, MINATEC Campus, F-38054 Grenoble, France \\ gael.pillonnet@cea.fr
}

\begin{abstract}
This paper presents a $95 \%$ power-efficient dutycycled LDO-assisted voltage selector (LAVS) for fine grained spatial and temporal voltage scaling in FDSOI $28 \mathrm{~nm}$ technology. LAVS enables 200ns/V controlled transitions between three power rails over a 0.5-to-1V range while maintaining the digital activity of the supplied load. During transitions, current and voltage detections are proposed to protect power rails from reverse current. LAVS has a $13 \% \mathrm{Si}$ area overhead to drive a $0.2 \mathrm{~mm}^{2}$ digital load. Thanks to a 100MHz-bandwidth LDO, which is only enabled during transition to save power consumption, the voltage selector also maintains a smooth voltage transition even if a digital load suddenly changes its activity factor $(4 \mathrm{mV} / \mathrm{mA}$ load transient). LAVS achieves 30pJ energy dissipation per voltage transition which is negligible compared to the power consumed by the digital load (50mW@0.2 $\mathrm{mm}^{2}$ ). This therefore allows a MHz dynamic voltage scaling rate.
\end{abstract}

Keywords - Voltage Selector, LDO, Dynamic Voltage Scaling, Voltage Regulator, FDSOI.

\section{INTRODUCTION}

Dynamic voltage scaling (DVS) is a conventional solution to reduce the energy dissipation of digital circuits by dynamically adjusting the digital power supply in order to find the best trade-off between energy dissipation and calculation speed for a given workload requirement. In addition, a highperformance computing processor is now divided into multiple cores which operate at different frequencies and where their individual workload changes dynamically. The power tree therefore has to be reviewed to address each core.

One off-chip power supply per island is a costly solution to set the best energy point of each core. Therefore, to reduce the PCB surface area, BoM (Bill of Materials) and allow rapid $V_{D D}$ switching, fine grained DVS can be done using multiple on-die DC-DC converters (no external component needed) as suggested in [1-3] and shown in Figure 1. However, their lowpower densities (10's of $\mathrm{mW} / \mathrm{mm}^{2}$ in deep CMOS technology) compared to the digital power density (10's of $\mathrm{W} / \mathrm{mm}^{2}$ ) has negated the benefits of a fully-integrated power tree due to its costly silicon overhead. The low density is mainly due to the low quality of on-chip inductor and capacitor compared to their off-chip counterparts [4]. Furthermore, an external DC-DC converter is still needed to step-down the available DC-bus voltage e.g. $12 \mathrm{~V}$ to an admissible level i.e. $1.8 \mathrm{~V}$ in order not to operate the switching transistors of on-chip converters at a higher rate than the voltage rating of the chosen CMOS technology [5].

Awaiting the ultimate power-tree CMOS integration, [6] proposes a reasonable trade-off between $\mathrm{PCB}$ and $\mathrm{Si}$ area saving where only power-rail selectors are integrated in the digital die to address individual power islands from a discrete set of shared external converters. Fig. 1 shows the typical power chain for $\mathrm{M}$ digital cores. $\mathrm{M}$ dedicated voltage selectors are fully integrated on chip which selects the optimal voltage $V_{\text {CORE }}$ for a given core's workload requirement between $N V_{D D}$ $(\mathrm{N}<\mathrm{M})$. The $\mathrm{N} \mathrm{V}_{\mathrm{DD}}$ power rails are generated from $\mathrm{N}$ off-chip shared DC-DC converters. [7] shows that just three different $\mathrm{V}_{\mathrm{DD}}(\mathrm{N}=3)$ are sufficient for near-ideal minimal energy point tracking over a large targeted operating frequency range. In this way, a power tree with only three external power supplies allows fine grained DVS for a multiple-core digital system. The benefit of this solution is the higher power density of on-chip voltage selectors compared to on-chip DC-DC converters as by nature, they do not need any flying passive components.

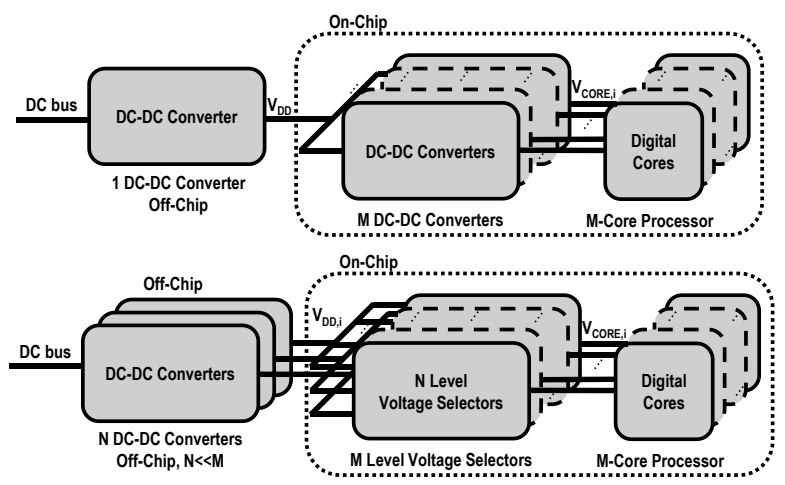

Fig. 1. Power-Tree Integration in a Multicore Processor using Independent Voltage Domains for Fine Grained DVS.

However, the hot switching, i.e. $\mathrm{V}_{\mathrm{CORE}}$ switching when the digital core remains active, is challenging. If the power paths are not controlled, some cross-currents between $\mathrm{V}_{\mathrm{DD}, \mathrm{i}}$ occur and the $\mathrm{V}_{\mathrm{CORE}}$ slew rate depends on the digital activity and power network. To avoid turning off the digital core at each $\mathrm{V}_{\mathrm{CORE}}$ transition, we propose a topology called LAVS by assisting the power-rail selector using a linear regulator (LDO). By using LAVS, the $\mathrm{V}_{\text {CORE }}$ transition is controlled while both 
maintaining digital activity and preserving it from a crosscurrent between different voltage rails $\mathrm{V}_{\mathrm{DD}}$,i. In the following sections, the LAVS topology and sequencing are described, and then the experimental results are discussed and compared to the state-of-the-art.

\section{VOLTAGE SELECTOR TOPOLOGY}

\section{A. LAVS System Overview}

The LAVS topology is shown in Figure 2. It is composed of a fully-integrated voltage selector which selects the core voltage $\mathrm{V}_{\mathrm{CORE}}$ between three shared voltage rails $\left\{\mathrm{V}_{\mathrm{L}}, \mathrm{V}_{\mathrm{M}}, \mathrm{V}_{\mathrm{H}}\right\}$ generated from an external DC-DC converter (out of the scope of this paper) in the range of $0.5-1 \mathrm{~V}$. Digital word SEL [1-2] selects the input voltage and a TR edge starts the voltage transitions (synchronized with external clock). The aim is to maintain a constant voltage slew rate $(200 \mathrm{~ns} / \mathrm{V})$ under any condition (voltage, activity factor, etc.) and a less than 5\% DC voltage drop at full load (50mA@1V) outside transitions. LAVS is composed of three LDO-assisted power-switches $\mathrm{M}_{\mathrm{i}}$, a voltage ramp generator, a 100ns delay block, shared current/voltage-mode comparator and a digital state machine. A single LAVS was conceived to drive a $0.2 \mathrm{~mm}^{2}$ digital core (400pF equivalent load on the $\mathrm{V}_{\mathrm{CORE}}$ node) and fully integrated in 28nm FDSOI technology with no external component. Multiple LAVS can be distributed to drive individual $0.2 \mathrm{~mm}^{2}$ power islands.

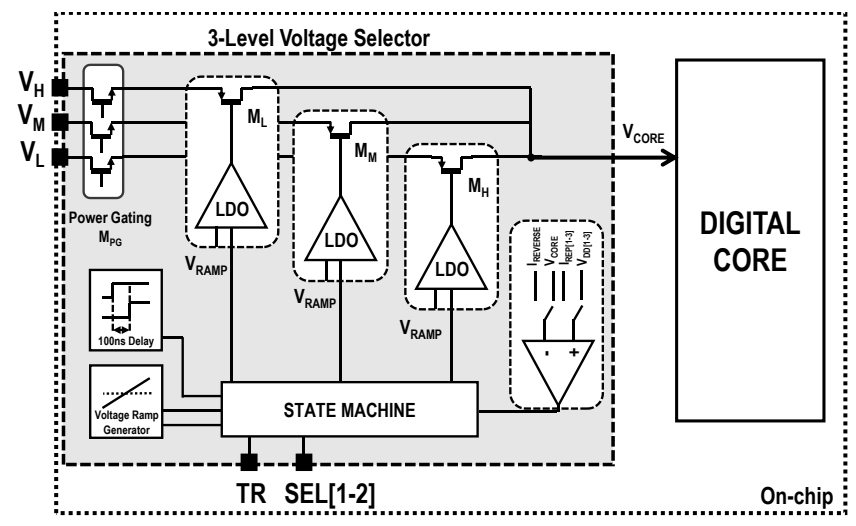

Fig. 2. Proposed 3 power-rail LDO-assisted Voltage Selector.

During transitions, the selected power switch acts as an LDO by using a super source follower structure (Section III) so the $V_{\text {CORE }}$ follows $V_{\text {RAMP }}$ in order to enforce the $V_{\text {CORE }}$ slew rate. The LDO bandwidth maintains a $4 \Omega$ output impedance at $100 \mathrm{MHz}$, thus preserving $\mathrm{V}_{\mathrm{CORE}}$ from over/undershoot when the load current varies suddenly during voltage transitions.

To provide current leakage reduction in power gating mode, thick-oxide transistors $\mathrm{M}_{\mathrm{PG}, \mathrm{i}}$ have been introduced in series with thin-oxide transistors $\mathrm{M}_{\mathrm{i}}$. The equivalent on-state resistance of $M_{i}$ in series with $M_{P G}$ is $1 \Omega$ worst case $\left(125^{\circ} \mathrm{C}\right.$, worst process corner) outside the voltage transition in order to have less than a $50 \mathrm{mV}$ voltage drop when one $\mathrm{V}_{\mathrm{i}}$ rail is selected.

\section{B. Switching Sequencing}

Figure 3 shows the sequencing for up- and down-voltage transitions between $\mathrm{V}_{\mathrm{H}}$ and $\mathrm{V}_{\mathrm{L}}$. The TR digital signal triggers the beginning of the transition, starting the voltage ramp and the delay blocks.

If the up-transition is selected, the $\mathrm{SW}_{\mathrm{H}}$ transistor toggles in LDO mode (super source follower mode) and $\mathrm{SW}_{\mathrm{L}}$ transistor is still turn-on. To prevent cross-current between $V_{L}$ and $V_{H}$, the current through $\mathrm{SW}_{\mathrm{H}}$ is checked by turning on the comparator in current-mode, called CM-C, a topology which will be described later. At $t_{R M}$, the CM-C detects that the current $I_{L}$ is negative, and so a charge flows towards $\mathrm{V}_{\mathrm{L}}$ meaning $\mathrm{V}_{\mathrm{L}}$ begins to receive energy. Then, the state machine turns off $\mathrm{SW}_{\mathrm{L}}$ to stop the reverse current. Between $t_{R M}$ and $t_{R H}, S W_{H}$ is still in LDO mode to continuously turn on the path between $\mathrm{V}_{\mathrm{H}}$ and $\mathrm{V}_{\mathrm{CORE}}$ with a controlled slew rate (see later). The comparator is only activated between $t_{R L}$ and $t_{R M}$ to save power consumption when no transition occurs.

In a down-transition, $\mathrm{SW}_{\mathrm{H}}$ switches from on-state to $\mathrm{LDO}$ mode (pull-down mode) until $\mathrm{V}_{\text {CORE }}$ reaches $\mathrm{V}_{\mathrm{L}}+\Delta \mathrm{V}_{\mathrm{L}}$ where $\Delta \mathrm{V}_{\mathrm{L}}=10 \mathrm{mV}$. At $\mathrm{t}_{\mathrm{FL}}, \mathrm{SW}_{\mathrm{H}}$ is turned off and $\mathrm{SW}_{\mathrm{L}}$ is enabled in order to connect $\mathrm{V}_{\mathrm{CORE}}$ to the final voltage $\mathrm{V}_{\mathrm{L}}$. Now, the shared comparator acts as a voltage comparator between $\mathrm{t}_{\mathrm{FH}}$ and $\mathrm{t}_{\mathrm{FL}}$ and is disabled outside.

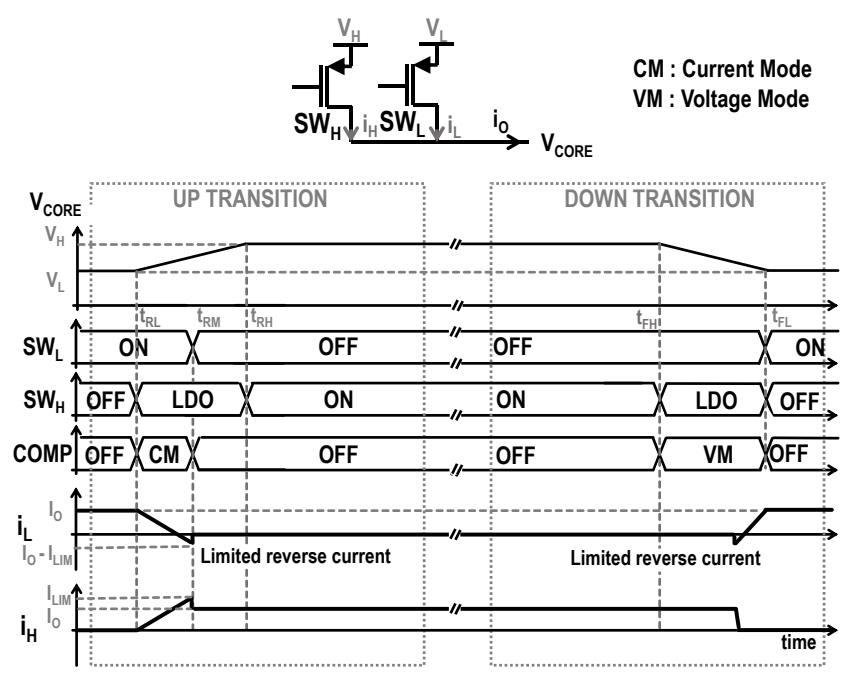

Fig. 3. Sequencing during up- and down-Transitions.

\section{Energy Consumption during Voltage Transition}

The energy cost of one transition has to be minimized to allow a high voltage transition rate and thus a better dynamic energy point tracking for each digital core. During the voltage transitions which last less than 100ns, LAVS consumes $300 \mu \mathrm{W}$ on average. Therefore, it costs less than $30 \mathrm{pJ}$ per transition which is negligible compared to a digital load activity (50mW@1V), if the voltage switching rate is lower to 10's of MHz. Outside the voltage transition, the LDO control and comparator are turned off to save quiescent power. When $\mathrm{V}_{\mathrm{CORE}}$ is maintained on a voltage rail, LAVS shows a $32 \mu \mathrm{W}$ power consumption, less than $1 \%$ of the driven digital core. In sleep mode, i.e. no DVS is needed, LAVS consumes less than $3 \mu \mathrm{W}$.

\section{IMPLEMENTATION}

Figure 4 shows the schematic of the voltage selector connected to the higher voltage rail $\mathrm{V}_{\mathrm{H}}$. The power switch $\mathrm{M}_{\mathrm{H}}$ is driven by a super source follower (SSF) topology. During an 
up-transition, $\mathrm{M}_{\mathrm{SSF}}$ is biased by the ramp voltage and shifted by one threshold voltage. Then, the ramp generator is precharged to $\mathrm{V}_{\mathrm{CORE}}-\mathrm{V}_{\mathrm{TH}}$ at the beginning of the transition to start the LDO reference voltage at $\mathrm{V}_{\mathrm{CORE}}$ at the beginning of the transition.

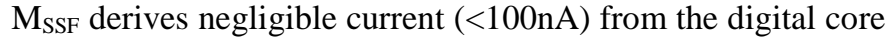
if $\mathrm{V}_{\mathrm{CORE}}<\mathrm{V}_{\mathrm{RAMP}}-\mathrm{V}_{\mathrm{TH}}$ to set $\mathrm{V}_{\mathrm{BIAS}}$ and then modulate $\mathrm{V}_{\mathrm{G}, \mathrm{H}}$ to set the voltage slew rate. There are two current sources $(\mathrm{I}=50 \mu \mathrm{A})$ and a cascade transistor link $\mathrm{V}_{\mathrm{BIAS}}$ to $\mathrm{V}_{\mathrm{G}, \mathrm{H}}$. When $\mathrm{V}_{\text {CORE }}$ pulls up to $\mathrm{V}_{\mathrm{H}}, \mathrm{V}_{\mathrm{G}, \mathrm{H}}$ is pulled down to zero in order to achieve the lowest on-state resistance for $\mathrm{M}_{\mathrm{H}}$. During down-transitions (pull-down mode), $\mathrm{M}_{\mathrm{PD}}$ is connected to the ramp voltage and pulls down $\mathrm{V}_{\text {CORE }}$ if the core voltage decreases at a lower rate than the required slew rate $(200 \mathrm{nV} / \mathrm{s})$ due to a low digital activity factor. $R_{P D}$ is sized to ensure a discharge of $400 \mathrm{pF}$ equivalent core capacitor in 100ns. Outside down-transitions, $\mathrm{M}_{\mathrm{PD}}$ is disabled.

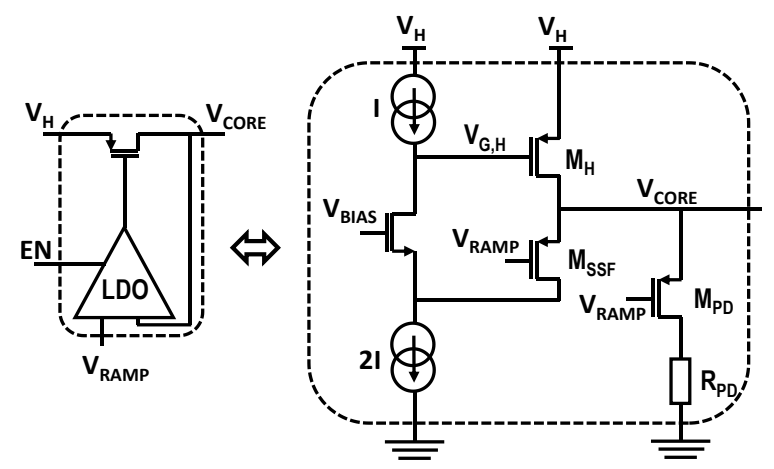

Fig. 4. Voltage Switches assisted by LDO during transitions.

Figure 5 shows the shared comparator composed of a fullydifferential amplifier and second-stage folded-cascade operational amplifier followed by a Schmitt trigger. During the up- and down-transitions, LAVS power consumption is $300 \mu$ and $240 \mu \mathrm{A}$, respectively. The comparison is made in a $2 \mathrm{~ns}$ delay and $2 \mathrm{mV}$ offset at $3 \sigma$. In voltage mode, $V_{\text {CORE }}$ is compared to the final desired voltage. In current mode, a voltage is generated by the reference current $I_{\text {REF }}$ and the measured reverse current which are then compared.

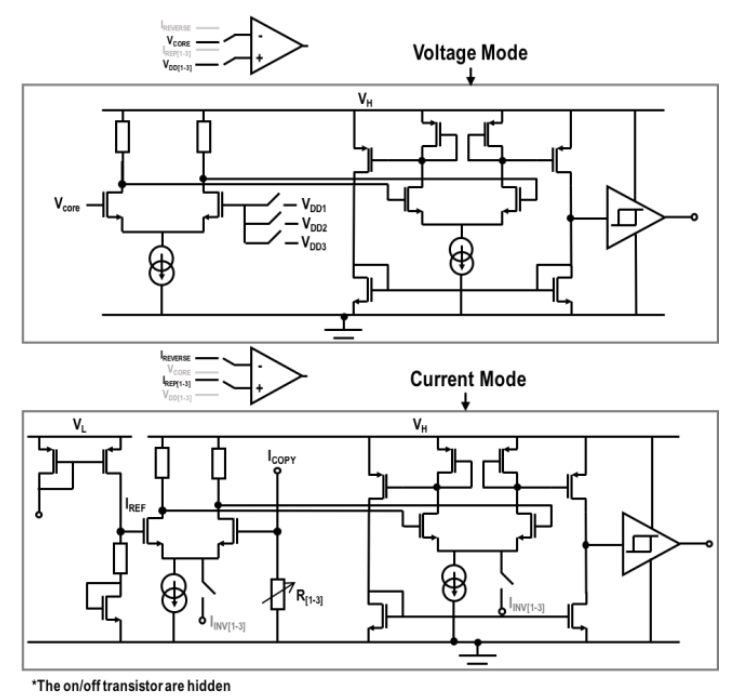

Fig. 5. Shared Comparator: Voltage and Current Mode.
The LAVS with an associated $0.2 \mathrm{~mm}^{2}$ digital core has been fabricated in FDSOI 28nm technology (Fig. 6). Three power rails $(0.5,0.75$ and $1 \mathrm{~V})$ are received from three external DCDC converters. The digital core is composed of a set of representative gates i.e. critical path replica, to mimic real digital core activity. The die area of LAVS is $0.027 \mathrm{~mm}^{2}$ $\left(0.045 \mathrm{~mm}^{2}\right.$ with power gating transistors) corresponding to $13 \%$ of the digital core area. No external component is needed e.g. no decoupling cap on the $\mathrm{V}_{\mathrm{CORE}}$ node.
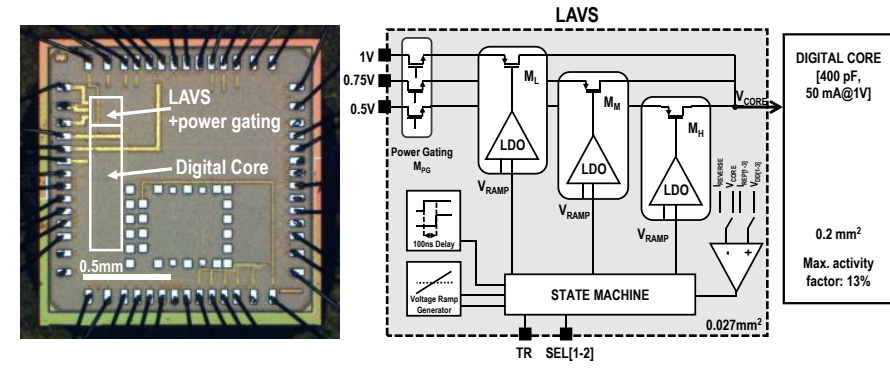

Fig. 6. LAVS with its Digital Load and Die Photograph.

\section{MEASUREMENT RESULTS}

The LAVS has been measured during up- and downtransitions for different workload conditions i.e. constant and variable activity factors. In Figure 7, the down-transition from 0.75-to-0.5V ( $\mathrm{V}_{\mathrm{M}}$ to $\left.\mathrm{V}_{\mathrm{L}}\right)$ shows a linear decrease of the $\mathrm{V}_{\mathrm{CORE}}$ with a controlled $200 \mathrm{~ns} / \mathrm{V}$ slew-rate with only $15 \mathrm{mV}$ dynamic undershoot below $\mathrm{V}_{\mathrm{L}}$. The digital load has a constant $13 \%$ activity factor corresponding to a current variation of 21mA@0.75V and 4mA@0.5V. The transition lasts 50ns and costs $15 \mathrm{pJ}$.

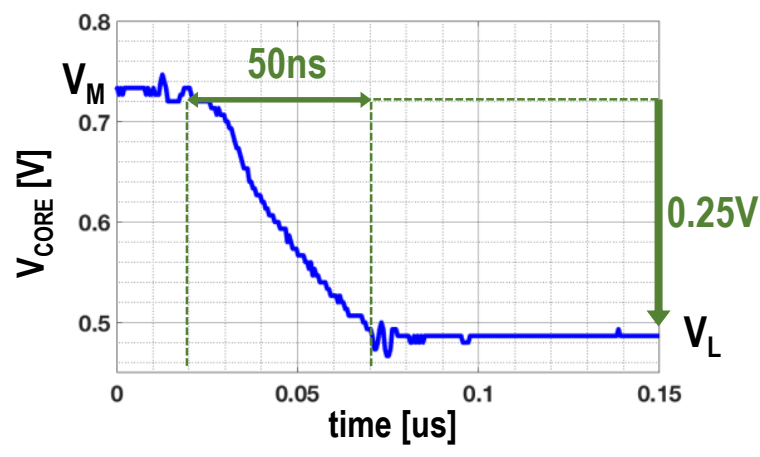

Fig. 7. Core Voltage during down-Transitions with Constant Activity Factor.

The up-transition from 0.75 -to- $1 \mathrm{~V}$ is shown in Figure 8 where the digital load still has a constant activity factor i.e. 21to-50mA current variation. The transition lasts $50 \mathrm{~ns}$ thanks to the controlled slew rate produced by the $\mathrm{SW}_{\mathrm{H}}$ in $\mathrm{LDO}$ operation (pull-down mode). $\mathrm{V}_{\mathrm{CORE}}$ is kept higher than $0.95 \mathrm{~V}$ ( $1 \mathrm{~V}$ minus $5 \%$ ) when the digital core rail is connected to $\mathrm{V}_{\mathrm{H}}$ with the maximum activity factor $\left(\mathrm{I}_{\mathrm{CORE}}=50 \mathrm{~mA} @ \mathrm{~V}_{\mathrm{H}}\right)$. The maximum reverse current (not shown in Fig. 8) provided from $\mathrm{V}_{\mathrm{M}}$ is below $20 \mathrm{~mA}$ during the voltage transition. 


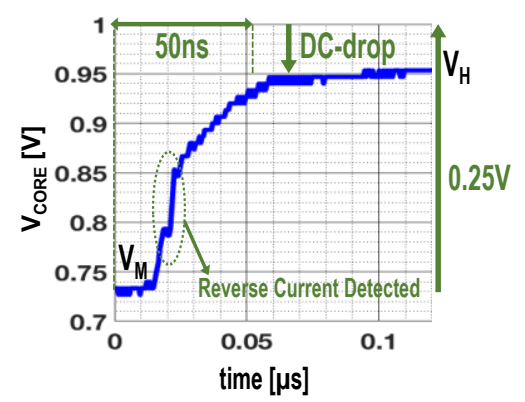

Fig. 8. Core Voltage during up-Transitions with Constant Activity Factor.

Figure 9 shows the $\mathrm{V}_{\mathrm{H}}$-to- $\mathrm{V}_{\mathrm{L}}$ transition when the current varies from 0.3 to $50 \mathrm{~mA}$ which mimics a workload variation. As $\mathrm{SW}_{\mathrm{H}}$ acts as the LDO, a fast regulation is performed to smooth $\mathrm{V}_{\mathrm{CORE}}$ due to the load transient whose equivalent is $4 \mathrm{mV} / \mathrm{mA}(0.2 \mathrm{~V}$ undershoot for a full current variation 0-to$50 \mathrm{~mA})$. The load transient response is measured without any extra decoupling capacitor on $\mathrm{V}_{\mathrm{CORE}}$ (only the intrinsic $400 \mathrm{pF}$ of the digital load). LAVS maintains a minimal voltage operating point i.e. $0.5 \mathrm{~V}$ to avoid blackout or timing violation in the digital load during the transition. The down-transition is done in $100 \mathrm{~ns}$ equivalent to $200 \mathrm{nV} / \mathrm{s}$.

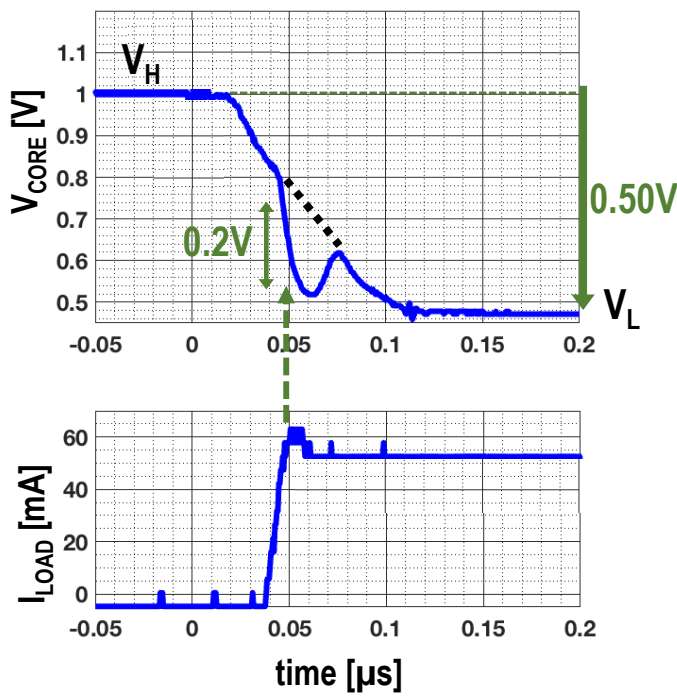

Fig. 9. Core Voltage during down-Transitions with Variable Activity Factor.

Table 1 compares the performance of the LAVS to the stateof-the-art. With a fully-integrated power tree option, the power density of our LAVS is two orders of magnitude higher than the best-in-class fully-integrated DC-DC converters in CMOS technologies without high-density capacitance options [1-3]. Compared to [4], we control the slew-rate i.e. $200 \mathrm{~ns} / \mathrm{V}$ of the voltage transition while maintaining sub- $\mu$ s transition time and low area overhead (13\% of digital load area) without turning off the load during transition.
TABLE I. COMPARISON WITH STATE-OF-THE-ART

\begin{tabular}{|c|c|c|c|c|}
\hline Metric & [1] & [2] & [3] & This Work \\
\hline Technology & 22nm FinFET & $28 \mathrm{~nm}$ FDSOI & $28 \mathrm{~nm}$ FDSOI & $28 \mathrm{~nm}$ FDSOI \\
\hline Digital System & Graphics core & Processor & Processor & Multicore processor \\
\hline Technique & LDO/SC & $\mathrm{sC}$ & Simultaneous SC & Voltage Selector \\
\hline Input Voltage & $0.65-1.05$ & 1.8 & $1,1.8$ & [0.5-1.0] x 3 rails \\
\hline Output Voltage & $0.38-0.92$ & $0.2-1.1$ & $0.5,0.67,0.9$ & {$[0.5-1.0 \mid \times 3$ rails } \\
\hline Slow-rate [ns/V] & - & 134 & $60^{*}$ & 200 \\
\hline $\begin{array}{l}\text { Efficiency. Maximum } \\
\text { power density } \\
{\left[\mathrm{W} / \mathrm{mm}^{2}\right]}\end{array}$ & - & 0.27 & 0.3 & $\begin{array}{c}\quad 5 \\
\text { without power gating }\end{array}$ \\
\hline $\begin{array}{l}\text { Maximum load } \\
\text { power }[\mathrm{mW}]\end{array}$ & - & $196^{*}$ & 65 & 50 \\
\hline $\begin{array}{c}\text { Quoted efficiency } \\
{[\%]}\end{array}$ & $\begin{array}{l}73 \text { (SC), } \\
84 \text { (LDO) }\end{array}$ & 72.5 & $80-86$ & $\begin{array}{c}>95^{* *} \\
\text { (measured value) }\end{array}$ \\
\hline
\end{tabular}

SC: Switched-Capacitor Converter

*extract from paper results. ${ }^{\star \star}$ An ideal voltage converter assumed in the voltage selector inputs.

\section{CONCLUSION}

We have demonstrated a compact and efficient 3-level voltage selector over 0.5 to $1 \mathrm{~V}$ which acts as an LDO during the transition in FDSOI $28 \mathrm{~nm}$ to perform fine grained DVS. The high-power density $\left(5 \mathrm{~W} / \mathrm{mm}^{2}\right)$ and power efficiency (>95\%) of LAVS compared to on-die DC-DC converters allows fine spatial DVS granularity with a small number of external DC-DC converters (here, three). The controlled 200ns/V slewrate and $30 \mathrm{pJ} /$ transition also allow fine temporal DVS granularity i.e. 10's of MHz DVS rate. The digital core power rails can be switched by maintaining the digital activity which allows hot switching. The LAVS power consumption in active mode corresponds to $0.1 \%$ of the digital load contribution which thus enables a seamless integration in many distinct power regions.

\section{REFERENCES}

[1] S.T. Kim et al., "Enabling wide autonomous DVFS in a $22 \mathrm{~nm}$ graphics execution core using a digitally controlled hybrid LDO/switchedcapacitor VR with fast droop mitigation," IEEE International Solid-State Circuits Conference, p. 154-155, 2015.

[2] T. Souvignet et al., "A Fully Integrated Switched-Capacitor Regulator With Frequency Modulation Control in 28-nm FDSOI," IEEE Transactions on Power Electronics, vol. 31, no. 7, pp. 4984-4994, 2016.

[3] B. Zimmer et al., "A RISC-V Vector Processor With SimultaneousSwitching Switched-Capacitor DC-DC Converters in $28 \mathrm{~nm}$ FDSOI," IEEE Journal of Solid State Circuits, vol. 51, no. 4, pp. 930-942, 2016.

[4] Y. Pascal et al., "Efficiency Comparison of Inductor-, Capacitor-, and Resonant-Based Converters Fully Integrated in CMOS Technology," IEEE Journal of Emerging Technology on Circuits and Systems, vol. 5, no. 3, pp. 421-429, 2015

[5] G. Pillonnet et al., "Effect of CMOS Technology Scaling on FullyIntegrated Power Supply Efficiency," IEEE International Conference on Integrated Power Electronics Systems, 2016

[6] K. Craig et al., "A 32 b 90 nm Processor Implementing Panoptic DVS Achieving Energy Efficient Operation From Sub-Threshold to High Performance," IEEE Journal of Solid State Circuits, vol. 49, no. 2, pp. 545-552, 2014.

[7] Y. Akgul, "Energy-efficient control through power mode placement with discrete DVFS and Body Bias," New Circuits and Systems Conference, 2015 